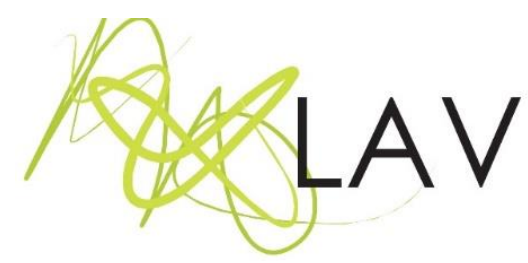

\title{
Entre o estranhamento e à espreita: um inventário de ideias para ensaiar criação em educação
}

\author{
Between estrangement and lurking: an inventory of ideas to rehearse creation in \\ education
}

\section{Resumo}

Carolina Goulart Kneipp ${ }^{i}$ Universidade Federal do Rio Grande do Sul

Cristian Poletti Mossii

Universidade Federal do Rio Grande do Sul

O presente artigo resulta de uma investigação a nível de Iniciação Científica (da autora deste texto e orientada pelo seu co-autor), a qual estabelece suas ações dentro de um projeto de pesquisa mais amplo que tem como desafio propor possíveis articulações entre o conceito de 'criação' (DELEUZE, 1999) e a noção de 'docência'. Assim, considerando a docência não como mera reprodutora de saberes, mas como campo de atuação que envolve, antes de tudo, criação, o texto expõe o recorte de um momento de formação em um curso de licenciatura em artes visuais. Optou-se por destacar a proposta operada na pesquisa aqui abordada, de produzir um inventário de ideias com a principal motivação de, a partir de fragmentos que convidam ao pensamento, experimentar brechas inventivas, isto é, possíveis linhas de fuga dentro do modelo formativo tradicional onde a criação possa aparecer como potência no ensaio (LARROSA, 2004, 2016) de docências singulares.

Palavras-chave: criação, docência, formação inicial, inventário de ideias, brechas inventivas.

\begin{abstract}
This article results from an investigation at the level of Scientific Initiation (by the author of this text, advised by the co-author), which establishes its actions within a broader research project whose challenge is to propose possible articulations between the concept of 'creation' (DELEUZE, 1999) and the notion of 'teaching'. Thus, considering teaching not as a mere reproducer of knowledge, but as a field of action that involves, above all, creation, the text exposes the cut of a moment of formation in a graduation course in visual arts. It was decided to highlight the proposal carried out in the research here, to produce an inventory of ideas with the main motivation of experimenting with inventive gaps from fragments that invite thought, that is, possible escape lines within the traditional formative model where creation can appear as power in rehearsal (LARROSA, 2004, 2016) of singular teaching processes.
\end{abstract}

Key-words: creation, teaching, initial formation, inventory of ideas, inventive gaps. 


\section{Articulações entre docência e criação}

Que espaços há para a criação na docência? Como possibilitar lugares para a criação em meio à formação em licenciatura em artes visuais? Que visualidades, leituras e escritas povoam docências que criam e se criam em educação das artes visuais? Compreendendo à docência como terreno fértil para "atos de criação pedagógica" (CORAZZA, 2013, p. 204) e a criação sempre como "um processo de auto-criação, de criação de si; ou seja, um diferenciar, diferenciando-se" (CORAZZA, 2013, p. 98), o presente artigo resulta do desdobramento de uma pesquisa a nível de Iniciação Científica, intitulada "De-formação à espreita na docência em artes visuais: um inventário de ideias para ensaiar criação em educação" (da autora deste texto e orientada pelo seu co-autor), a qual estabelece seu plano de pensamento e suas ações dentro de um projeto de pesquisa mais amplo chamado: "Docência e criação em educação das artes visuais: povoamentos entre visualidades, leituras e escritas" que se ocupa em pensar e problematizar as relações que podem se dar entre essas duas instâncias - docência e criação - em um curso de licenciatura em artes visuais, especialmente no que concerne às visualidades, leituras e escritas produzidas e/ou apropriadas por estudantes em formação inicial dentro de um curso de licenciatura em Artes Visuais, compreendendo essas como matérias de expressão de ideias e de percursos inventivos/formativos trilhados pelos acadêmicos licenciandos.

Desse modo, a investigação que se sucede busca seu referencial teórico principalmente nas produções advindas do campo das chamadas filosofias da diferença e tem como pressuposto a ideia de que sempre há criação na docência, com foco especificamente nas possibilidades de criação durante o processo de formação docente em artes visuais. Não apenas a criação como criatividade - resolução genuína para problemas, sendo esta apenas uma parte do ato de criação (CORAZZA, 2013) - tampouco a criação dotada de uma carga de genialidade, como produto e fundamento de uma mente já formada, mas a criação como a invenção de sempre novos problemas. Não um já saber, mas um aprender constante de uma subjetividade em movimento.

Criação, contudo, que não é inerente a nenhuma atividade/prática/contexto, mas que depende de certo trabalho, de uma postura que torne tais processos favoráveis à sua manifestação. Para Deleuze (1999), esse trabalho rumo ao ato de criação envolve o mergulho em um domínio específico, em um território, em uma área do conhecimento.

Revista Digital do LAV - Santa Maria - vol. 12, n. 1, p. 4 - 17 - jan./abr. 2019 ISSN 1983 - 7348 http://dx.doi.org/10.5902/1983734836657 
Nossa defesa, neste texto, é a de que a produção desse domínio passa antes por um exercício de estranhamento, o que dependeria, nesse caso, da incorporação de uma postura 'à espreita' (noção que que será aprofundada mais adiante) para tornar o terreno em que o sujeito se encontra mais profícuo às possibilidades infindáveis de criação.

Se tratando, portanto, das possibilidades de criação em meio ao campo da docência, tomo como lugar de investigação o meu próprio percurso enquanto estudante de graduação em um curso de licenciatura em artes visuais para explorar onde estão/como estimular situações de criação dentro do contexto de formação docente. Para isso, construo ao longo da pesquisa um inventário de ideias em educação. Esse inventário opera com a motivação de me colocar 'à espreita' de possíveis brechas inventivas, espaços mínimos dentro do cenário educacional, para tornar visível as possibilidades de experimentar a criação ao longo do processo de formação docente e, em meio a esses acontecimentos, produzir docências singulares e inventar outros sentidos para a prática docente.

\section{A potência de estranhar}

[...] E acontece o seguinte: quando estranho uma pintura é aí que é pintura. E quando estranho a palavra aí é que ela alcança o sentido. E quando estranho a vida aí é que começa a vida. Clarice Lispector (Água Viva, 1973)

Estranhar tem a ver com certa dose de surpresa, de curiosidade - e às vezes incômodo diante de algo ou alguém que se desconhece. Estranhamos culturas diferentes, pessoas com hábitos distintos, situações inusitadas, ações realizadas pela primeira vez. Mas também nos acostumamos. E ao passo que há essa naturalização das experiências, as situações de estarrecimento vão diminuindo e a tendência é a substituição do questionamento pela instauração da certeza. Na tentativa de domar o fluxo dos acontecimentos cotidianos e organizar o excesso de informações, tomamos alguns aspectos como resolvidos e buscamos abrigo no acúmulo de convicções, seguros de que assim podemos nos movimentar confortavelmente em um mundo tão inseguro. Por outro lado, estranhar nos afasta dessa suposta segurança, desacomoda nossas percepções e gera desconforto. Nesse sentido, conforme propõe Kastrup (2016, p. 3), podemos nos relacionar com a incerteza daquilo que estranhamos como "algo perigoso, demasiado grande, que não é possível combater" ou como algo que "[...] dá lugar à invenção, fazendo emergir atitudes de engajamento e participação que procuram originar estratégias de construção de um mundo comum". E é precisamente a invenção que se origina desse desconforto cognitivo que, aqui, nos interessa.

Revista Digital do LAV - Santa Maria - vol. 12, n. 1, p. 4 - 17 - jan./abr. 2019 ISSN 1983 - 7348 
Como em todas as áreas do conhecimento, no campo da educação coexistem inúmeras teorias que exploram os mecanismos e as possibilidades metodológicas da docência. No entanto, é notável a repetição e valorização de uma visão que se configura como reprodução de modelos de atuação docente, quase receitas de bolo que ensinam passo a passo quais são as abordagens corretas e mais eficientes de determinado assunto dentro de sala de aula, em detrimento de abordagens mais inventivas e processuais que valorizem as singularidades. Um amplo universo de possibilidades reduzido ao que 'dá certo' e a maior parte do processo formativo preso à égide das grandes certezas sobre a educação.

Mas em todo contexto onde há a predominância de um grande discurso, vozes dissonantes se proliferam. No caso dos percursos de formação docente, produzindo um movimento inverso ao que busca atingir a postura do 'exímio docente' ou do 'bom professor', estão os espaços de experimentação e criação de estudantes de graduação, respiros que possibilitam pensar e inventar docências singulares. Esses espaços não estão separados do cotidiano formativo, mas existem nas sutilezas, nas brechas que podem se abrir a partir de olhares que estranham e permitem a si mesmos desconfiar daquilo que veem.

\section{Nota no 1 - Aprender com o desconforto}

Exercício proposto: criar esculturas utilizando o corpo, sozinho ou em grupo, nos espaços do Instituto de Artes. (A professora não pôde estar presente).

sem professora. chuva. frio. não gosto de me sentir observada, exposta. não conheço a maioria dos colegas. qual o propósito disso? as outras turmas estão aprendendo a soldar. pra quê usar o corpo? preguiça. vontade de ir embora. mas eu me locomovi até aqui. acordei cedo. deve ter um sentido. tiro o casaco. vou tentar uma vez, e se não der certo, vou embora. assino a chamada e vou, é simples. ok, proponho a tentativa ao grupo. alguém se levanta e se junta à experiência. conversamos. temos uma ideia. prática. acho que é por aí. e se tentarmos de novo? de outro jeito? descoberta. já não é constrangedor. o corpo agora faz parte de algo maior. me observo. me movimento. vontade de continuar. mais ideias. outros colegas colaboram. agora eu sei o nome dela! chão gelado e molhado. não importa. esqueço de ir embora. discussão acalorada. mais propostas. parece estar funcionando. entendi alguma coisa. o tempo agora passa rápido. lugares que eu não tinha percebido até então. percebo o espaço de modo mais atento. análises minuciosas. os corpos ganham outro significado nesse espaço e tempo. fotografamos tudo. vejo as fotos. criamos. hora de ir embora. fome. empolgação. o que criamos? criamos uma aula 
(Fragmento do caderno pessoal da autora que constituiu o princípio do inventário de ideias em educação proposto pela pesquisa).

Segundo Virgínia Kastrup (2001), são exatamente as situações que nos despertam estranhamento que se configuram em ocasiões de aprendizagem. Sobre essa questão, a autora nos apresenta o exemplo da viagem: quando viajamos e nos deparamos com um novo ambiente, as atividades mais cotidianas tornam-se problemáticas, de modo que o estranhamento e tensão entre o saber anterior e a experiência presente nos forçam a aprender, a construir um novo domínio cognitivo e uma outra maneira de realizar tais atividades. Além disso, ao retornarmos à nossa cidade, nos tornamos mais sensíveis a aspectos que antes nos passavam despercebidos e a experiência da recognição se transforma em problematização, gerando outras ocasiões de aprendizagem.

Com essa imagem em atravessamento, Kastrup constrói o argumento de que o processo de aprendizagem não se dá por meio da recognição, isto é, a partir do reconhecimento, prático ou consciente, de um objeto, ideia ou situação. Pelo contrário, defende a autora que a aprendizagem opera pela via da problematização e envolve a capacidade de criar novos problemas. Nesse sentido, somos forçados a pensar, a ir além, de modo que acolher e habitar incertezas é uma questão de aprendizagem:

Não se trata da aprendizagem mecânica ou intelectual, nem daquela que se baseia na transmissão de informações. A educação não é uma questão de informação, nem de explicação, nem de formação de opinião. A questão aqui é a da aprendizagem inventiva, que inclui a capacidade de problematizar, de criar novos problemas. Trata-se de instaurar uma política cognitiva da invenção (KASTRUP, 2016, p. 4).

E ao criar novos problemas, o ato de criação encontra-se em um polo muito distante da ideia modernista de 'criatividade' enquanto genialidade de uma mente 'bem formada' e com 'boa vontade', mas como ação que se confunde com a própria ação involuntária do pensamento (DELEUZE, 2006, 2010; DELEUZE; GUATTARI, 1992). É nessa perspectiva que ensinar/aprender envolve, essencialmente, criação. A produção da ideia como algo que não é natural, mas forjado nos encontros fundamentais com signos que nos forçam a pensar (DELEUZE, 2010).

Assim, é a partir desses olhares que estranham, desses corpos disponíveis à incerteza que surgem as brechas para a experimentação e para a criação dentro do contexto de formação docente, gerando uma aprendizagem que não se resume à transmissão de informações vertical, de alguém que ensina para alguém que aprende, mas que produz rupturas e linhas de fuga dentro das produções de sentido lineares. Trata-se, de certa forma, de tornar-se 
estrangeiro em seu próprio campo de atuação/formação. De pensar, como sugere Anelice Ribetto (2011), a formação de professores desde a experiência - e não como experimento - e tomá-la como um espaço menor, um espaço de resistência e de desconstrução de um suposto campo maior, o campo da formação de professores.

\section{'A' de animal}

Gilles Deleuze (1988-1989), ao abordar a letra 'A de Animal' em seu Abecedário (série de entrevistas concedidas à Claire Parnet), apresenta-nos a noção de 'Animal' como um ser fundamentalmente à espreita. Uma existência atenta que vê, ouve e fareja minuciosamente todo o seu entorno, estando sempre à espera de um novo estímulo a lhe afetar - ou melhor: que vive num estado de abertura de sentidos onde absolutamente tudo pode the ser estimulante, desde que seja capaz de ampliar seus atributos. No caso de um animal propriamente dito, atribui-se essa característica a questões instintivas ligadas à sobrevivência, como a preocupação com a defesa do território e a busca por alimento. Porém, se transportarmos essa ideia para o cenário descrito anteriormente, nos parece haver muito o que pensar a partir do ' $A$ ' de animal de Deleuze.

A partir da perspectiva de uma docência "contaminada por encontros com pensamentos, conceitos, ideias, caminhos outros que não aqueles especialmente dedicados aos espaços educacionais" (PACHECO, 2015, p. 127), pensamos que o percurso formativo também se constrói em meio a esses encontros - incluindo aqueles que ocorrem fora do cenário educacional - e é colocando-se à espreita dos mínimos acontecimentos presentes no cotidiano formativo que possibilitamos 'estranhar' os modelos prescritivos e exercer a criação de outras maneiras de existir enquanto docente.

Tendo como princípio a ideia de que a criação "não é um processo espontâneo, ou seja, não se dá em um sujeito relaxado e passivo, nem se configura como uma ação voluntária onde o sujeito possui uma intenção ou uma meta ativamente buscada" (KASTRUP, 2007, p. 60), compreendemos a noção de 'espreita' como uma postura do que a autora chama de "ativa receptividade": não se trata de ir atrás de ideias, nem aguardar passivamente ser acometido por elas; o ato de ter uma ideia se assemelha mais a um encontro do que a uma busca, porém trabalha-se para que esse encontro aconteça.

No mais, o pensamento criador "não vai por si, mas se realiza por meio de uma experimentação e movimentos que buscam dar expressão à ideia" (KASTRUP, 2007, p. 63). E é na tentativa de gerar tais movimentos, portanto, que nos propomos a produzir, a partir da incorporação de uma postura 'à espreita' do campo da formação docente, um

Revista Digital do LAV - Santa Maria - vol. 12, n. 1, p. 4 - 17 - jan./abr. 2019 ISSN 1983 - 7348 http://dx.doi.org/10.5902/1983734836657 
inventário de ideias em educação (Figura 01), tendo a arte - em especial as artes visuais - não apenas como conteúdo ou como área de saber estabelecida, mas como "uma perspectiva de transformação de subjetividades e de mundos constituídos" (KASTRUP, 2007, p. 59).

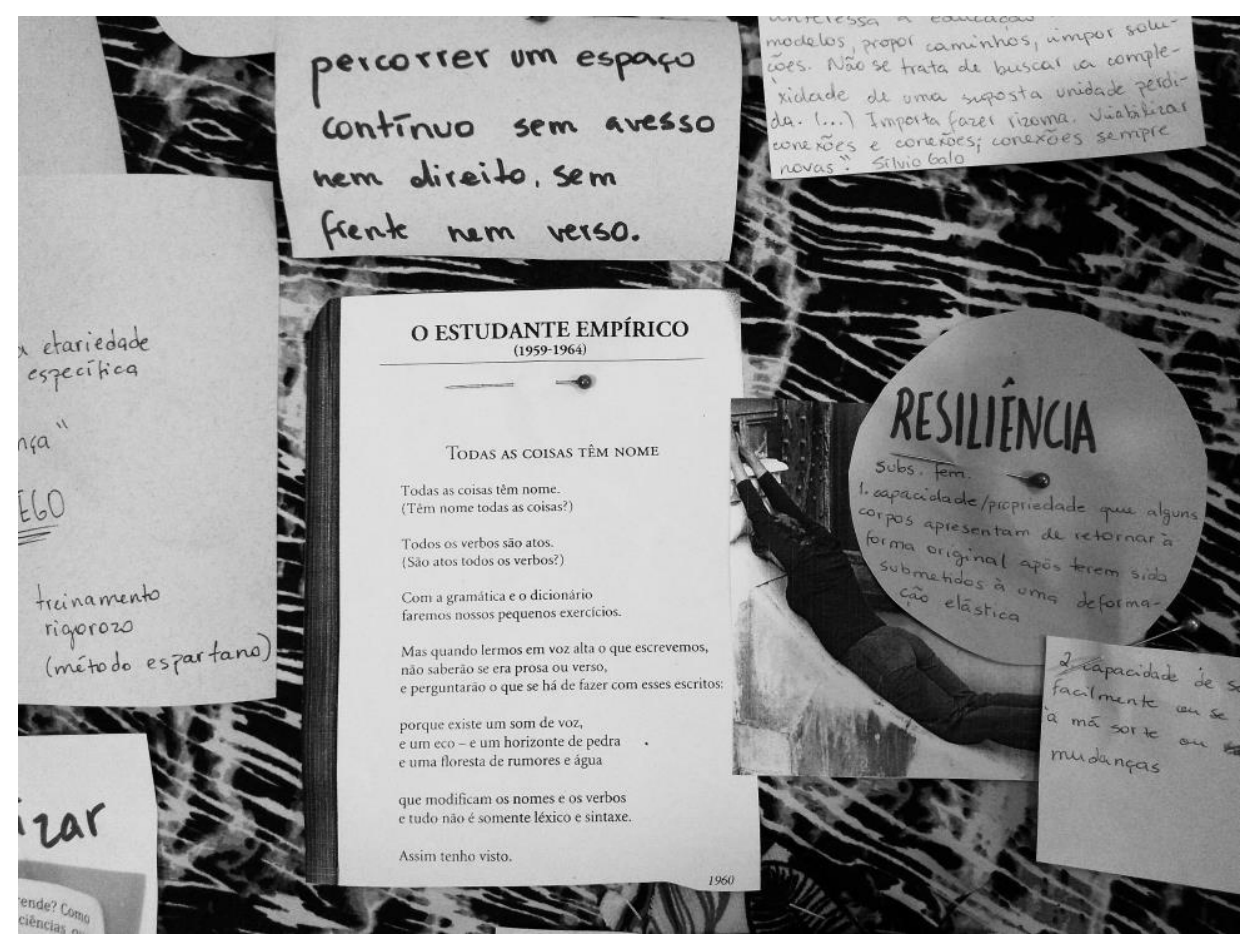

Figura 01. Fragmento do inventário de ideias em educação. Trata-se de uma superfície em tecido, de dimensões variáveis, onde se sobrepõem recortes, anotações, frações de textos e imagens que se apresentam como disparadores de ideias, estímulos que abrem caminho para atos de criação ao longo do processo de formação docente.

Fonte: Acervo pessoal dos autores.

A fabricação do inventário surge então como uma estratégia de atravessar a formação inicial a partir da incorporação de uma atitude à espreita, com o objetivo primeiro de colecionar afetos, ideias que deem expressão e materialidade às experiências de criação na docência; mas ao longo de seu desenvolvimento se transforma e começa a se apresentar como um lugar de ensaio, de exercício de si e do próprio pensamento em ação.

Em virtude disso, devido ao seu caráter experimental, temos pensado a produção do inventário como um lugar para 'ensaiar' formas de docência, operando com a noção de 'ensaio' a partir de Jorge Larrosa $(2004,2016)$. Segundo o autor,

[...] poder-se-ia dizer, talvez, que o ensaio é uma atitude existencial, um modo de lidar com a realidade, uma maneira de 
habitar o mundo, mais do que um gênero da escrita. [...] Poder-seia dizer, talvez, que o ensaio é o modo experimental do pensamento, o modo experimental de uma escrita que ainda pretende ser uma escrita pensante, pensativa, que ainda se produz como uma escrita que dá o que pensar; e o modo experimental, por último, da vida, de uma forma de vida que não renuncia a uma constante reflexão sobre si mesma, a uma permanente metamorfose (LARROSA, 2004, p. 32).

A seguir, portanto, além de apresentarmos um pouco mais do modo como temos pensado a noção de 'ensaio' na produção do inventário de ideias em educação, buscaremos expor também uma produção de sentidos que insurge a partir do próprio inventário enquanto objeto de natureza múltipla, o qual se abre a infindáveis re-montagens e re-articulações a partir de seus elementos constituintes. Trata-se, portanto, da cristalização de um processo (possível, contingente), sempre em vias de se fazer, mas que aqui territorializamos momentaneamente para a escrita deste texto.

\section{Ensaiando educações possíveis}

"O 'ensaio' - que é necessário entender como experiência modificadora de si no jogo da verdade, e não como apropriação simplificadora de outrem para fins de comunicação - é o corpo vivo da filosofia, se, pelo menos, ela for ainda hoje o que era outrora, ou seja, uma 'ascese', um exercício de si, no pensamento"

(FOUCAULT, 1998, p. 13).

Ensaiar, aqui, envolve um olhar para a formação docente do ponto de vista dos fragmentos, de algo que nos pareça expressivo e sintomático e a isso dar "uma grande expressividade" (LARROSA, 2004, p. 32). Segundo Larossa, "o ensaísta não sabe bem o que busca, o que quer, aonde vai. Descobre tudo isso à medida que anda. Por isso [...] para quem o caminho e o método são propriamente ensaio" (2004, p. 27). Nesse sentido, operar a partir da lógica do ensaio coloca a prática como um lugar de experiência, de exercício de si, de incessante problematização e aprendizado.

Metodologicamente falando, encarar essa pesquisa como uma operação ensaio é converter também seu método em problema de pesquisa e tornar seu fazer como criação metodológica. Isto é, uma vez que nos desfazemos de qualquer cisão entre campo prático e teórico, operamos com os dados produzidos e a partir da investigação e experimentação dos espaços de criação inventamos caminhos metodológicos possíveis. Segundo Jorge Larrosa (2016, p. 26), 
A peculiaridade do ensaio não é sua falta de método, mas a de que mantém o método como problema sem nunca tê-lo como suposto. Uma vez fossilizado, o método é uma figura linear, retilínea. $O$ ensaio, no entanto, seria uma figura de caminho sinuoso, um caminho que se adapta aos acidentes do terreno. O caminho linear, retilíneo é o caminho daquele que sabe previamente aonde vai, e traça, entre ele e seu objeto, a linha mais curta, mesmo que para realizá-la tenha que passar por cima de montanhas e rios. O método tem a forma de uma estrada ou via férrea que ignora o tema. Ao contrário, o ensaísta prefere o caminho sinuoso, o que se adapta aos acidentes do terreno $[\ldots]$.

Compreende-se, assim, o inventário de ideias como um lugar para ensaiar docências singulares, que nos convoca a pensar e a criar a partir do mínimo, das descontinuidades do percurso formativo e de situações cotidianas. Não com a pretensão de somente agrupar memórias em uma superfície, caixa ou diário, mas de convidar a demorar-se nesses acontecimentos e extrair deles o máximo, esgotá-los para assim problematizar e criar a si mesmo nesse processo de captura do presente. Produzir, portanto, outros caminhos e derivações, outras possibilidades ainda não pensadas e desdobrar suas relações escapando à lógica dos modelos pré-existentes.

\section{Inventário de quê?}

Uma rápida visita ao dicionário nos mostra que a palavra 'inventário' pode designar a "relação dos bens deixados por alguém que morreu", uma "lista indiscriminada, registro, relação, rol de mercadorias, bens, etc." ou a "descrição ou enumeração minuciosa de coisas em geral". Ou seja, ela inclui as ideias de legado e de arquivo ao mesmo tempo, relacionando-se aos atos de listar, enumerar, registrar, catalogar e colecionar. Mas para além dessas noções, é possível ainda identificar uma afinidade explícita do termo com "invento/invenção", o que o levaria a se aproximar - por vias oblíquas - também dos campos da poiésis, do fazer criativo (MACIEL, 2012, p. 29).

É nesse sentido mais próximo ao termo 'invento/invenção' que o inventário de ideias em educação se materializa e processualmente tem se constituído. A partir da recusa de acontecimentos estrondosos em prol de uma postura atenta às miudezas da vida cotidiana e da formação, o inventário se desenvolve como uma superfície sensível onde se inscrevem fragmentos, situações que movimentam o pensamento, produzem encontros com ideias em educação e, consequentemente, rastros da invenção de si (KASTRUP, 2007) durante o processo de formar-se singularmente docente. Isto é, uma ação experimental de sobrepor/justapor e tornar visível os movimentos, leituras, escritas e afetos surgidos e sentidos em espaços dentro e fora da universidade. Atividade de recorte, colagem, costura, desenho, mapeamento e deslocamento, produção de distâncias e aproximações que em 
inter-relação com a noção de aprendizagem inventiva, se manifesta, sobretudo, como uma experiência de problematização. Segundo Kastrup (2001, p. 24),

O aprendiz artista não se conforma com seus limites atuais, mas toma-se a si mesmo como objeto de uma invenção complexa e difícil. O aprendiz é constrangido à tarefa de reinventar-se. A aprendizagem, sob a perspectiva da arte, envolve então uma atitude-limite, que faz escapar da polarização sujeito-objeto, interior-exterior, e habitar a zona de fronteira. A atitude-limite, no caso, não consiste em trabalhar dentro de limites fechados e que não poderiam ser ultrapassados, mas em trabalhar transpondo limites, aprendendo a aprender.

Dessa forma, a produção de um inventário de ideias em educação tem como uma de suas motivações salientar os entrecruzamentos entre criação e docência à medida em que nos coloca à espreita de elementos que deflagrem a tomada de ideias em meio aos processos inventivos de aprendizagem que podem se dar ao longo do percurso de formação docente em artes visuais. Explora, assim, as maneiras como a criação na docência se manifesta a partir de estímulos inusitados os quais, muitas vezes, extrapolam aquilo que é previsto dentro de um cenário educacional. Resulta na criação de um objeto que não depende de um sujeito, mas que se apresenta como um artefato capaz de ativar processos de subjetivação heterogêneos diluindo um Eu-criativo e convocando ao pensamento.

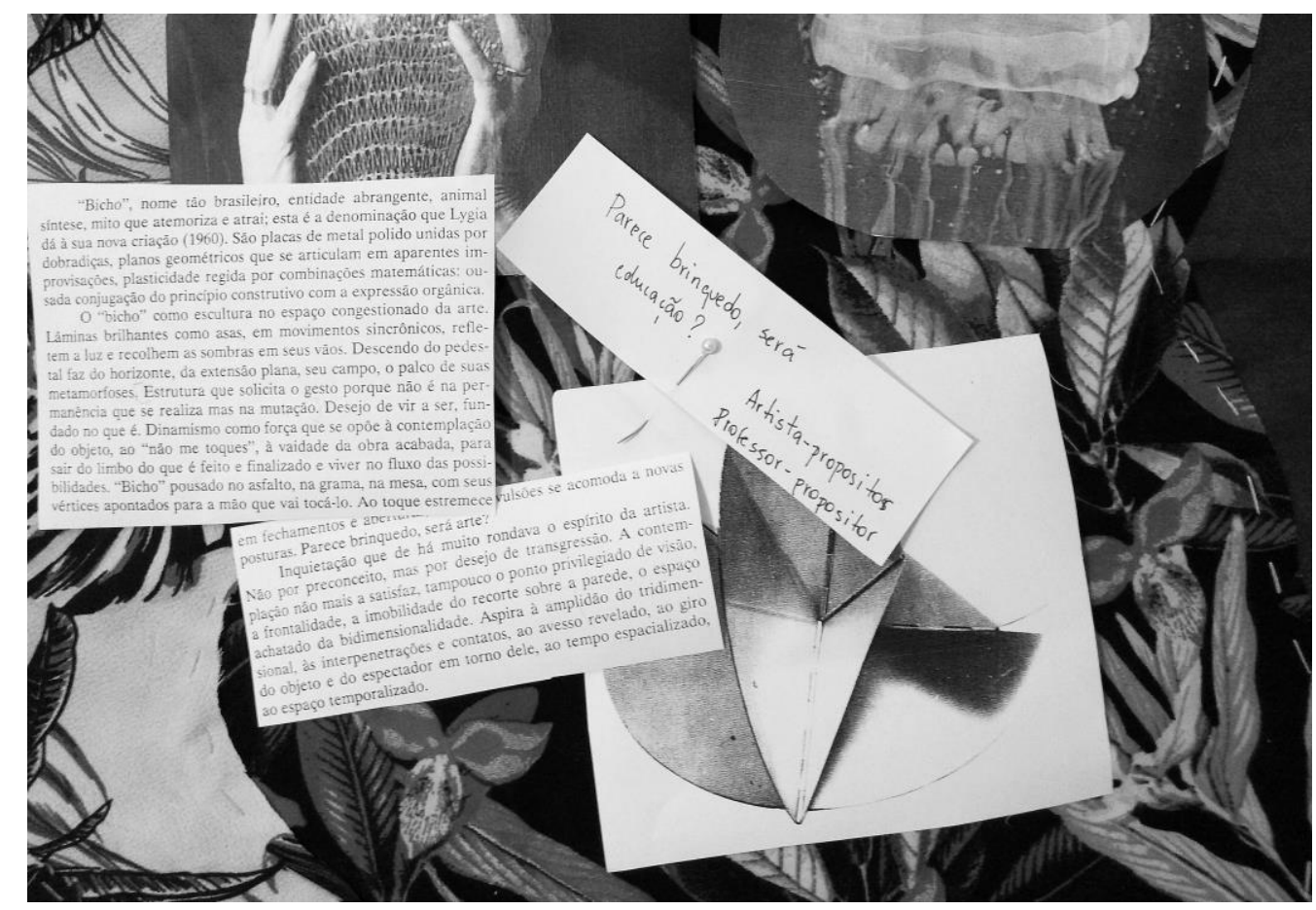

Figura 02. Fragmento do inventário de ideias em educação.

Fonte: Acervo pessoal dos autores.

Revista Digital do LAV - Santa Maria - vol. 12, n. 1, p. 4 - 17 - jan./abr. 2019 ISSN 1983 - 7348

http://dx.doi.org/10.5902/1983734836657 
Importante salientar que embora o inventário tenha tomado forma inicialmente como um objeto, uma espécie de tabuleiro feito de tecido onde se 'inventaria' fragmentos, reminiscências do percurso formativo, sua proposta não se limita a nenhuma forma: cada vez mais se distancia de sua configuração material e se expande enquanto desdobramento de uma postura investigativa/formativa e/ou uma invenção metodológica.

\section{Desarranjando formas e fôrmas}

Nessa perspectiva, ensinar/aprender algo - formar-se -, excede conhecer o que não se conhecia, simplesmente, ou 'decifrar', 'ler' um mundo que já estaria pronto esperando que a ele meramente nos adaptássemos (como uma fôrma), mas se amplia para de-formarse: inventar, criar, compor outros arranjos possíveis com o que vai afetando os corposdocentes pelo caminho, cunhar universos dentro do universo, desestabilizar o que parecia estável, mostrar outras possibilidades no que parecia dado.

Um processo de de-formação (TADEU, 2004), nessa perspectiva, não significa a perda da forma ou sua despotencialização, mas sim seu desarranjo ou decomposição inventivos, os quais geram o alargamento dos processos formativos em estado de multiplicidade. $A$ formação como lugar para exercícios de pensamento e experimentação que se iniciam ao escolhermos o caminho das incertezas e não das certezas, quando como o Animal de Deleuze, nos colocamos à espreita de sempre novos problemas.

Assim, o inventário de ideias em educação tem se tornado, para além de um objeto ou um artefato capaz de ativar processos de subjetivação, uma atitude, um modo de relacionarse com a docência e com o processo de formação docente sob a ótica da decomposição, da de-formação, da aprendizagem inventiva, do ensaio ininterrupto sem ponto de chegada pré-estabelecido, do estranhamento e da espreita. Poderia não tomar a forma material aqui exposta em tecido e recortes, poderia tomar outras formas de exposição e até mesmo não tomar nenhuma forma visível.

Nos interessa, assim, o que cada um escolhe para dizer de seu percurso formativo? Que conexões cada um trama e retrama entre os fragmentos que vão sendo encontrados pelo caminho ao formar-se e de-formar-se professor? Como cada um ensaia-se docente mediante as capturas que convidam ao pensamento dentro e fora da universidade, e se relaciona com esses vestígios os quais, mais do que encaminharem o estudante em 
formação inicial a uma fôrma, podem servir como ferramentas poderosas para ativar a multiplicidade ontológica do pensamento?

Com tais questões, portanto, encerramos este texto, entendendo-as como a proposição de caminhos para pensar a formação inicial e a docência, de um convite para operar com tais conceitos na prática cotidiana, para experimentá-los, alargá-los e inseri-los em novos contextos a fim de gerar novos ensaios e outras possíveis fissuras nos grandes discursos sobre educação, abrindo espaço para a potência dos atos criadores que atravessam a vida.

\section{Referências}

CORAZZA, S.M. O que se transcria em educação? Porto Alegre: UFRGS; Doisa, 2013.

DELEUZE, G. O abecedário de Gilles Deleuze. Realização de Pierre-André Boutang, produzido pelas Éditions Montparnasse, Paris. No Brasil, foi divulgado pela TV Escola, Ministério da Educação. Tradução e Legendas: Raccord [com modificações]. A série de entrevistas, feita por Claire Parnet, foi filmada nos anos 1988-1989.

DELEUZE, G. O ato de criação [Palestra de 1987, tradução José Marcos Macedo]. São Paulo: Folha de São Paulo, 1999.

DELEUZE, G. Diferença e repetição [tradução de Luiz Orlandi e Roberto Machado]. 2.ed. Rio de janeiro: Graal, 2006.

DELUZE, G. Proust e os signos [tradução de Antonio Piquet e Roberto Machado]. 2.ed. Rio de Janeiro: Forense Universitária, 2010.

DELEUZE, G.; GUATTARI, F. O que é a filosofia? [tradução de Bento Jr. e Alberto Alonso Muñoz]. Rio de Janeiro: Ed. 34, 1992.

FOUCAULT, M. História da sexualidade II. O uso dos prazeres. Rio de Janeiro: Graal, 1998.

KASTRUP, V. Aprendizagem, arte e invenção. Psicologia em estudo, Maringá, v. 6, n. 1, p. 17-27, jan./jun. 2001. 
KASTRUP, V. Flutuações da atenção no processo de criação. In: LECERF, E.; BORBA, S.; KOHAN, W. (Org.). Imagens da imanência - escritos em memória de H. Bergson. Belo Horizonte: Autêntica, 2007. p. 59-71

KASTRUP, V. Educação e invenção em tempos de incerteza. In: VOLZ, J.; PRATES, V. (Org.). Incerteza viva: processos artísticos e pedagógicos - 32a Bienal de São Paulo. São Paulo: Fundação Bienal de São Paulo, 2016. p. 1-5.

LARROSA, J. Operação ensaio: sobre o ensaiar e o ensaiar-se no pensamento, na escrita e na vida. Educação \& Realidade, Porto Alegre, v. 29, n. 1, p. 27-43, jan/jun. 2004.

LARROSA, J. O Ensaio e a escrita acadêmica. In: CALLAI, C.; RIBETTO, A. (Orgs.). Uma escrita acadêmica outra: ensaios, experiências e invenções. Rio de Janeiro: Lamparina, 2016. p. 17-30.

LISPECTOR, C. Água Viva. Rio de Janeiro: Artenova, 1973.

MACIEL, M.E. O inventário dos dias: notas sobre a poética de Leonilson. In: CASSUNDÉ, C.E.B; MACIEL, M.E.; RESENDE, R. (org.). Leonilson: Sob o peso dos meus amores. Porto Alegre: Fundação Iberê Camargo, 2012.

PACHECO, E.G. Arte, diferença e educação - um manifesto sobre formação de professores de arte. Revista da Fundarte. Montenegro, ano 15, n. 30, p. 126-140, jul./dez, 2015. Disponível em: <http://seer.fundarte.rs.gov.br/index.php/RevistadaFundarte/index>. Acesso em: 10 fev. 2018.

RIBETTO, A. Pensar a formação de professores desde a experiência e desde o menor da formação. Revista Reflexão e Ação, Santa Cruz do Sul, v. 19, n.2, p. 109-119, jul./dez. 2011.

TADEU, T. A filosofia de Deleuze e o currículo. (Coleção Desenrêdos; n.1). Goiânia, Faculdade de Artes Visuais, 2004.

\footnotetext{
' Graduanda do curso de Artes Visuais Licenciatura pela Universidade Federal do Rio Grande do Sul.

ii Professor Adjunto da Faculdade de Educação da Universidade Federal do Rio Grande do Sul (UFRGS), atuando junto ao Departamento de Ensino e Currículo e ao Programa de PósGraduação em Educação (PPGEdu) na linha de pesquisa Arte, Linguagem e Currículo. Possui Doutorado em Educação (2014) pelo Programa de Pós-Graduação em Educação (PPGE), na linha de pesquisa Educação e Artes e Mestrado em Artes Visuais (2010) pelo
} 
Programa de Pós-Graduação em Artes Visuais (PPGART), na linha de pesquisa Arte e Cultura, ambos pela Universidade Federal de Santa Maria (UFSM/RS) e com financiamento integral da CAPES. Graduação em Desenho e Plástica - Bacharelado e Licenciatura Plena (2004/2007), Pós-graduação - Especialização em Design para Estamparia (2008) na mesma instituição. Desenvolve estudos e pesquisas nas áreas de Artes Visuais e Educação e atualmente foca suas investigações na interface desses campos com as Filosofias da Diferença, tendo interesse especial pelas inter-relações entre processos de criação/invenção e docência. É membro pesquisador do Grupo de Estudos e Pesquisas em Arte, Educação e Cultura (GEPAEC) e do Grupo de Estudo e Pesquisa em Arte e Docência - ARTEVERSA, ambos vinculados ao CNPq.

Como citar esse artigo:

KNEIPP, Carolina Goulart; MOSSI, Cristian Poletti. Entre o estranhamento e à espreita: um inventário de ideias para ensaiar criação em educação. Revista Digital do LAV, Santa Maria: UFSM, v. 12, n. 1, p. 04-17, jan./abr. 2019. 